\title{
PEMBERDAYAAN IBU RUMAH TANGGA MELALUI PEMANFAATAN SUMBER DAYA LOKAL
}

DOI: https://doi.org/10.33024/jkpm.v4i4.3806

\author{
Viviana Murni ${ }^{1^{*}}$, Angelina Ofita Belo², Maria Ersi Diu³ ${ }^{3}$ Dominikus S \\ Jebarus ${ }^{4}$, Heronimus Samlan ${ }^{5}$ \\ 1,2,3,4,5 Universitas Katolik Indonesia Santu Paulus Ruteng, NTT
}

Disubmit: 04 Februari 2021 Diterima: 20 Februari 2021 Diterbitkan: 01 Agustus 2021

Email Korespondensi: vivianamurni0123@@gmail.com

\begin{abstract}
ABSTRAK
Kegiatan pengadian kepada masyarakat yang dilakukan bersamaan dengan pelaksanaan kuliah kerja nyata dilatarbelakangi oleh hasil observasi tim pengabdian kepada masyarakat, yaitu masyarakat desa Poco belum memanfaatkan hasil pertanian menjadi sesuatu yang bisa menambah penghasilan keluarga. Selain itu, Ibu rumah tangga belum aktif untuk membantu menambah pendapatan keluarga. Oleh karena itu, tim Unika Santu Paulus Ruteng mengadakan program pengabdian kepada masyarakat dengan memberdayakan para ibu rumah tangga kelompok basis gereja Santu Lukas Poco melalui pengolahan sumber daya lokal. Kegiatan ini bertujuan untuk mengembangkan potensi para ibu rumah tangga. Program ini dilakukan melalui beberapa tahap, yaitu observasi, perencanaan, pelaksanaan, dan evaluasi. Kegiatan ini dapat berpengaruh positif terhadap para ibu rumah tangga dalam menambah penghasilan keluarga. Para ibu rumah tangga menjadikan bolu pisang sebagai camilan natal dan usaha untuk menambah pendapatan mereka. Memanfaatkan hasil pertanian dan pemberdayaan para ibu rumah tangga merupakan hal yang sangat penting dan harus diperhatikan oleh berbagai pihak, terutama pemerintah desa.
\end{abstract}

Kata Kunci : Pemerdayaan Ibu Rumah Tangga, Pemanfaatan Sumber Daya Lokal

\begin{abstract}
Community service activities that were carried out simultaneously with the implementation of real work lectures are motivated by the results of the community service team's observations, namely that the Poco village community has not utilized agricultural products into something that can increase family income. In addtion, housewives have not been active in helping to increase family income. Therefore, the Indonesian Catholic University of Saint Paul Ruteng team held a community service by empowering church-based group housewives to the processing of local resources. This activity aim to develop the potential of housewives. This program was carried out through several stages, namely observation, planning, implementation, and evaluation. This program have a positive effect on housewives in increasing family income. The housewives use banana cake as a christmas snack are trying to increase their income. Utilizing agricultural products and empowering housewives are very important things that must be considered by various parties, especially the village goverment.
\end{abstract}

Keywords:empowerment of housewives, utilization of local resources 


\section{PENDAHULUAN}

Kelompok Basis Gereja (KBG) St. Lukas merupakan salah satu KBG yang terdapat di Paroki St. Montfort yang berada di desa Poco, Kecamatan Wae Ri'i, kabupaten Manggarai, Propinsi Nusa Tenggara Timur. KBG St. Lukas Poco berjarak $11 \mathrm{~km}^{2}$ dari Unika Santu Paulus Ruteng. Desa Poco berbatasan dengan beberapa wilayah, yaitu sebelah utara berbatasan dengan Benteng Poco, sebelah selatan berbatasan dengan Ndehes, sebelah barat berbatasan dengan Satar Ngkeling, dan sebelah Timur berbatasan dengan Compang Ndehes. Luas wilayah Desa Poco adalah 3,2 $\mathrm{km}^{2}$ dengan jumlah penduduk 1.350 jiwa, yang terdiri dari 570 laki-laki dan 780 perempuan. Rata-rata penduduk laki-laki bermata pencaharian petani dan perempuan sebagai ibu rumah tangga. Terdapat beberapa sumber daya lokal/hasil pertanian di paroki Poco, diantaranya kopi, cengkeh, pisang, dan lain.

Pisang merupakan salah satu hasil pertanian yang banya dihasilkan oleh para petani desa Poco. Senada dengan hal tersebut, pisang merupakan jenis buah-buahan yang mudah dan murah didapat karena sangat banyak dihasilkan di Indonesia. Produksi pisang di Indonesia yang cukup tinggi tidak sebanding dengan tingkat konsumsi masyarakat, sehingga mengakibatkan banyak pisang yang tidak dimanfaatkan karena daya simpan buah yang relatif singkat (Retno \& Nuri, 2011). Buah pisang mudah rusak dan cepat mengalami perubahan mutu setelah panen, karena memiliki kandungan air tinggi dan aktivitas proses metabolismenya meningkat setelah dipanen(Sayangbati dkk, 2013). Kulit pisang mengandung serat pangan dalam jumlah $50 \mathrm{~g} / 100 \mathrm{~g}$, sehingga merupakan sumber serat pangan potensial(Aryani dkk, 2018). Selain itu, Pisang (Musa paradisiaca) merupakan buah yang mengandung sumber karbohidrat, mineral serta vitamin B6 dan vitamin C yang tinggi (Miller, 2012). Kandungan karbohidrat sederhana dan kompleks yang ada pada pisang dapat bermanfaat sebagai sumber energi bagi tubuh. Buah pisang mempunyai kandungan gizi cukup tinggi ketimbang buah lainnya (Zaima dkk,2020). Program PKM dilaksanakan di KBG St. Lukas Paroki Poco dengan sasaran Para Ibu rumah tangga karena merupakan salah satu paroki dengan penghasilan pisang cukup tinggi tetapi tidak dimanfaatkan menjadi usaha yang bisa membantu menambah penghasilan masyarakat Paroki Poco. Selain itu, hasil panen masyarakat melimpah, sedangkan nilai jual tidak sebanding dengan waktu dan tenaga dalam merawat pisang. Pengolahan pisang lokal menjadi bolu pisang akan dijadikan sebagai camilan pada hari raya natal. Selain itu, pengolahan pisang menjadi bolu pisang akan dijadikan usaha mikro kecil menengah.

Perkembangan sektor industri dalam pembangunan di Indonesia tidak terlepas dari dukungan dan eksistensi industri kecil (Tambunan, 2011). Secara historis, eksistensi UMKM Indonesia sangat penting dalam kegiatan ekonomi domestik dengan menyumbang 99\% tenaga kerja negara (Petter \& Cathy, 2015). Di Uganda, UMKM berperan penting dalam menciptakan lapangan kerja yang memungkinkan tercapainya pertumbuhan dan pembangunan yang adil dan berkelanjutan (Hasan dkk, 2014). Oleh karena itu, UMKM dianggap sebagai penggerak pertumbuhan ekonomi dan pemerataan pembangunan di suatu negara berkembang. Selain itu, UMKM dapat mendorong persaingan regional, nasional, dan internasional untuk meningkatkan kualitas dan kapasitas produksi (Nurdin, 2019). Jaringan dalam UKM sangat tergantung kepada bagaimana pemilik UMKM mengatur proses jaringan dalam mengelolah kegiatan bisnis (Weerasiri, 2012). Zaman sekarang, semua orang berlomba-lomba mempromosikan produknya melalui teknologi (Wiyono, 2016).

Berdasarkan oservasi yang dilakukan oleh tim PKM Unika Santu Paulus Ruteng, ada pun permasalahan yang ditemukan yaitu relatif mudah untuk mengasumsikan bahwa relatif tidak sedikit masyarakat yang berpenghasilan 
rendah atau tergolong masyarakat miskin. Berkaitan dengan hal ini, belum banyak ibu rumah tangga aktif membantu meningkatkan ekonomi keluarga. Sejauh ini, belum ada sentuhan agar potensi para ibu rumah tangga diperdayakan dengan baik. Para ibu rumah tangga belum mendapat penyuluhan dan motivasi tentang bagaimana memanfaatkan potensi mereka sehingga memberi kontribusi dalam meningkatkan pendapatan kelurga. Penyuluhan dan pelatihan sangat membantu para iu rumah tangga dalam menemukan, menggerakkan, mengembangkan, dan meningkatkan potensi mereka. Potensi diri merupakan kemampuan dasar yang masih dipendam dan menunggu untuk diwujudkan menjadi seuatu kekuatan yang bisa diandalkan dalam diri (Wiyono, 200).

\section{MASALAH}

Salah satu permasalahan urgen yang ditemukan di desa poco adalah masyarakat belum memanfaatkan hasil pertanian dengan baik, tidak produktif dalam mengolah hasil pertanian menjadi suatu produk yang bisa menambah penghasilan mereka. KBG St. Lukas dengan hasil pertanian tertinggi adalah pisang tidak dapat mengolah pisang secara efektif. Hal ini disebakan oleh minimnya pengetahuan tentang pengolahan pisang menjadi produk yang inovatif. Untuk mengatasi persoalan tersebut, maka tim PKM Unika Santu Paulus melakukan pendekatan terhadap para ibu rumah tangga KBG St. Lukas untuk memanfaatkan hasil pertanian berupa pisang menjadi camilan tertentu, yaitu bolu pisang. Biaya pembuatan bolu pisang terjangkau dan bisa menjadi produk yang menunjang penghasilan para IRT.

\section{METODE}

Masyarakat KBG Santu Lukas Poco memiliki salah satu permasalahan yang sangat urgen, yaitu masyarakat tidak produktif dalam memanfaatkan sumber daya lokal. Salah satu sumber daya lokal yang dihasilkan oleh para petani desa poco adalah pisang. Pisang belum dijadikan hasil pertanian yang bisa digunakan untuk menambah pendapatan kelurga. Penduduk desa Poco sebagian besar merupakan petani dan desa Poco merupakan salah satu desa yang cukup dekat dengan perkotaan. Fenomena yang menjadi prihatin di desa ini, para ibu rumah tangga belum memberikan kontribusi dalam meningkatkan ekonomi keluarga. Hal ini disebabkan oleh kurangnya dukungan berupa penyuluhan dan pelatihan dari berbagai pihak terkait. Oleh karena itu, untuk menyelesaikan permasalahan yang terdapat di KBG St. Lukas Paroki Poco, tim PKM Unika Santu Paulus Ruteng memiliki solusi yang dilakukan melalui beberapa metode, yaitu observasi, perencanaan, pelatihan, dan evaluasi. Metode observasi dilakukan untuk mengetahui permasalahan yang dialami mitra, metode perencanaan berkaitan dengan tentang diversifikasi produk maka olahan yang berasal dari pisang, metode pelatihan yaitu melatihan para IRT mengolah pisang menjadi bolu pisang, sedangkan metode evaluasi digunakan untuk mengetahui kelebihan dan kekurangan mengenai program PKM yang dijalankan. Berikut adalah tabel pelaksnaan kegiatan PKM pada IRT KBG St. Lukas Paroki Poco. 
Tabel 1 pelaksanaan kegiatan PKM

\begin{tabular}{|c|c|c|c|}
\hline No & METODE & LANGKAH-LANGKAH & KEGIATAN \\
\hline 1. & Observasi & Melakukan observasi di lokasi & $\begin{array}{l}\text { Menemukanpokok } \\
\text { permasalahan dengan } \\
\text { menanyakan tentang } \\
\text { hasil pertanian dan } \\
\text { cara mengolahnya. }\end{array}$ \\
\hline 2. & Perencanaan & $\begin{array}{l}\text { a. Perijinan ke Paroki Poco } \\
\text { b. Koordinasi mitra terkait } \\
\text { kegiatan PKM }\end{array}$ & $\begin{array}{l}\text { - Mengantar surat ijin } \\
\text { untuk melakukan } \\
\text { PKM } \\
\text { - } \text { Menentukan lokasi } \\
\text { PKM } \\
\text { - Menentukan waktu } \\
\text { dan tanggal } \\
\text { pelaksanaan }\end{array}$ \\
\hline 3. & Pelaksanaan & $\begin{array}{l}\text { Penyuluhan dan pelatihan } \\
\text { pengolahan hasil pertanian } \\
\text { menjadi makanan ringan }\end{array}$ & $\begin{array}{l}\text { - Penyuluhan tentang } \\
\text { diversifikasi produk } \\
\text { makan olahan yang } \\
\text { berasal dari pisang } \\
\text { - Pelatihan } \\
\text { pengolahan pisang } \\
\text { menjadi camilan } \\
\text { bolu pisang }\end{array}$ \\
\hline 4. & Evaluasi & $\begin{array}{l}\text { Mengumpulkan tim PKM dan } \\
\text { mitra }\end{array}$ & $\begin{array}{l}\text { Berdiskusi tentang } \\
\text { hambatan, tantangan, } \\
\text { dan hal positif yang } \\
\text { diperoleh pada saat } \\
\text { pelaksanaan PKM demi } \\
\text { melancarkan kegiatan } \\
\text { selanjutnya. }\end{array}$ \\
\hline
\end{tabular}

\section{HASIL DANPEMBAHASAN}

Program PKM ini dilaksanakan di KBG St. Lukas dengan metode observasi, perencanaan, pelatihan, dan evaluasi. Para IRT mendapat pencerahan dan pelatihan tentang pengolahan hasil pertanian menjadi olahan yang bernilai ekonomis cukup tinggi. Program PKM ini dapat menyadarkan para IRT untuk tidak hanya bergerak dalam bidang pertanian, namun juga mengolah hasil pertanian menjadi produk bolu pisang. Program mendapat respon yang positif dari mitra, hal ini ditunjukkan dengan antusiame dan keterliatan mitra dalam kegiatan yang telah dilakukan berikut ini:

\section{a) Observasi dan Perencanaan}

Pada tahap observasi mencaritahu tentang permasalahan umumnya terjadi di Paroki St. Montfort Poco. Maka, ditemukan permasalahan urgen yaitu rendahnya pengetahuan masyarakat tentang pengolahan hasil pertanian menjadi produk yang dapat mendapat pendapatan mereka. Ditemukan bahwa produksi pisang cukup tinggi di Poco, tetapi belum dikelolah dengan baik. Sedangkan pada tahap perencanaan, tim Unika St. Paulus Ruteng membicarakan solusi dari persoalan yang ada, berdiskusi dengan mitra tentang pengolahan pisang menjadi bolu pisang. Tim Unika Santu Paulus Ruteng memutuskan untuk memilih para IRT KBG St. Lukas sebagai mitra karena alasan tertentu, yaitu sebagian besar para IRT di KBG ini tidak mempunyai pekerjaan tetap dan produksi pisang tertinggi 
terdapat di KBG St. Lukas. Pada tahap perencanaan, tim memberikan penyuluhan tentang alat dan bahan yang harus disiapkan. Selain itu, tim memberikan pelatihan cara mengolah pisang menjadi bolu pisang. Tim memberikan penyuluhan cara membuat bolu pisang agar tetap terjaga nilai manfaat dan gizinya. Tim memberikan pelatihan yang maksimal sehingga mitra memahami dengan baik cara membuat bolu pisang, pemahaman mereka mengenai pengolahan pisang menjadi produk yang bernilai cukup tinggi sangat menentukan kelanjutan kegiatan yang dilakukan.

b) Pelaksanaan

Pada tahap pelaksanaan, tim bersama mitra melakukan kegiatan berikut:

1) Menyiapkan alat dan bahan, yaitu pisang, tepung terigu, telur, soda kue, vanili, mentega, minyak goreng, gula, alat, loyang, pengocok kue, dan dandang.

2) Cara pembuatan, untuk ukuran 1 loyang, siapkan:

$>4$ buah pisang, dihaluskan

$>$ Kocok 2 butir telur sampai mengembang

$>$ Masukan $5 \mathrm{sdm}$ gula pasir

$>$ Masukan terigu sebanyak $16 \mathrm{sdm}$

$>$ Masukan minyak goreng $8 \mathrm{sdm}$

> Masukan soda dan vanili masing-masing $1 \mathrm{sdt}$

$>$ Semua bahan diaduk sampai rata

$>$ Oleskan loyang dengan mentega, kemudian balut dengan tepung secara merata

> Masukan adonan ke dalam loyang, kemudian dikukus dengan api sedang

> Bolu pisang siap dihidangkan

Semua kegiatan tersebut dilakukan secara bersama oleh tim PKM dan mitra, seperti yang tergambar berikut ini:

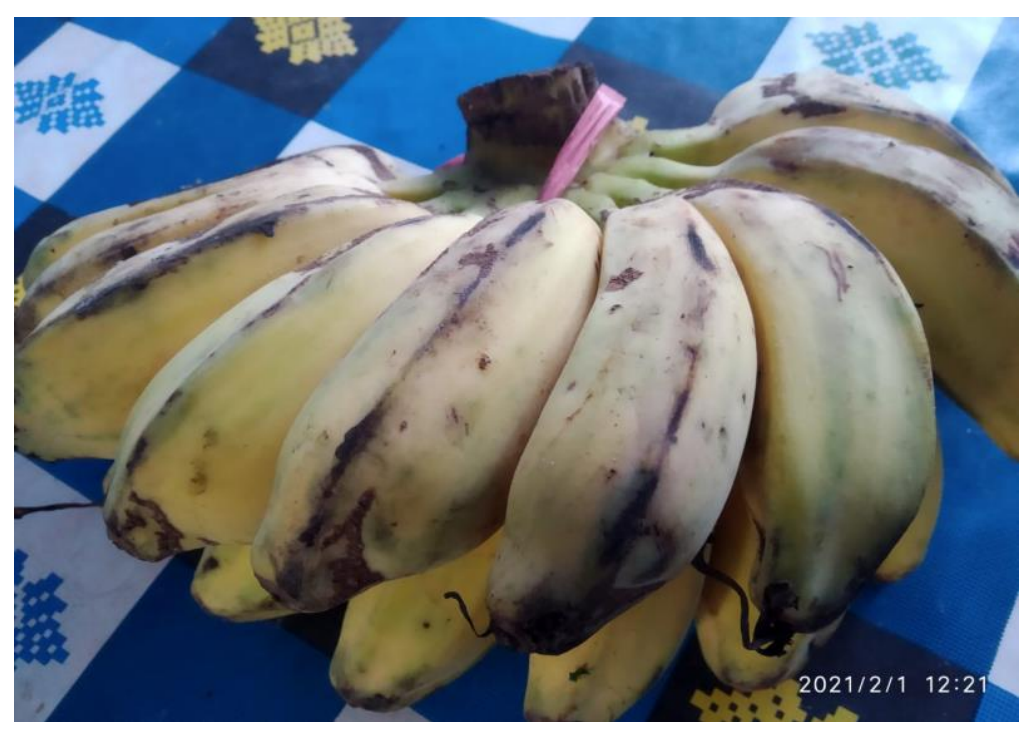

Gambar 2.1 Sumber Daya Lokal 


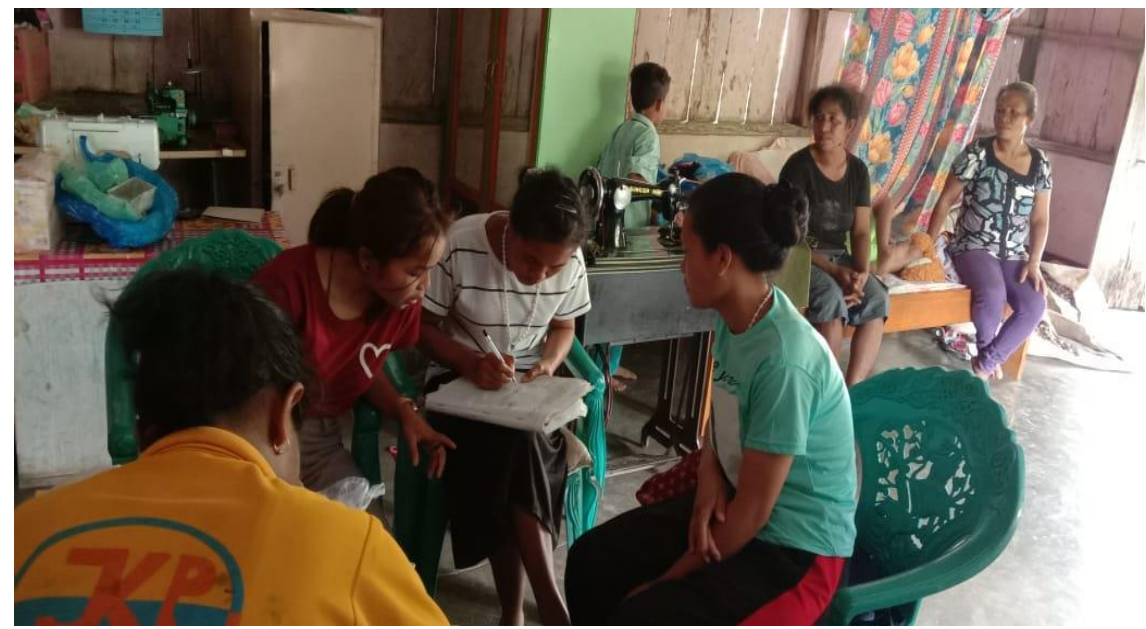

Gambar 2.2 mengidentikasikan alat dan bahan

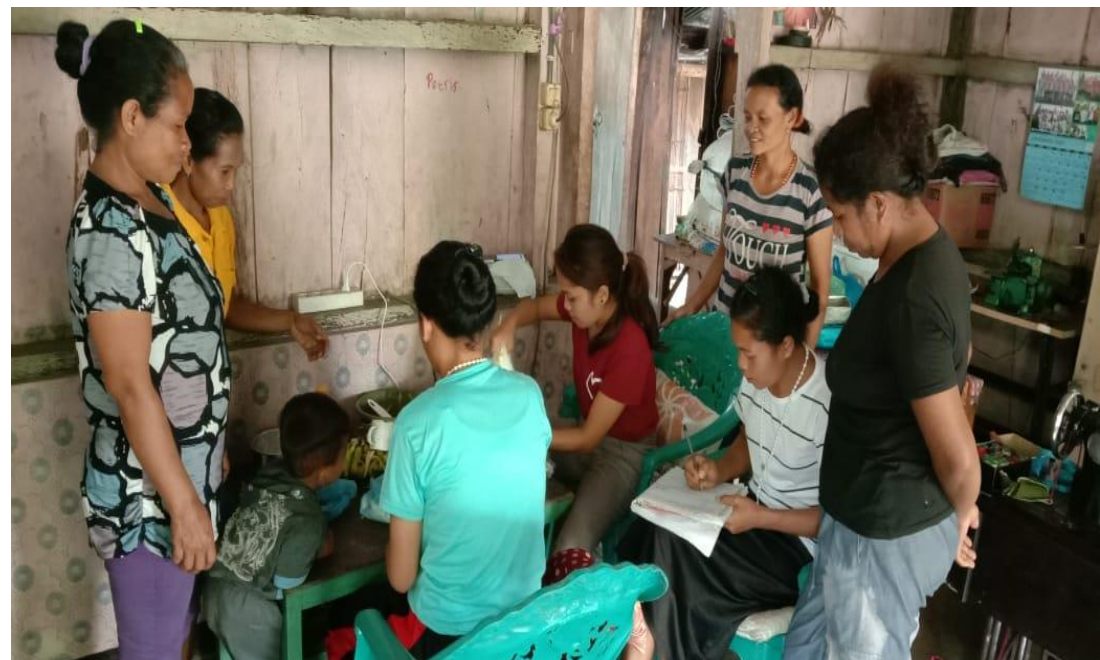

Gambar 2.3 Pembuatan Bolu Pisang

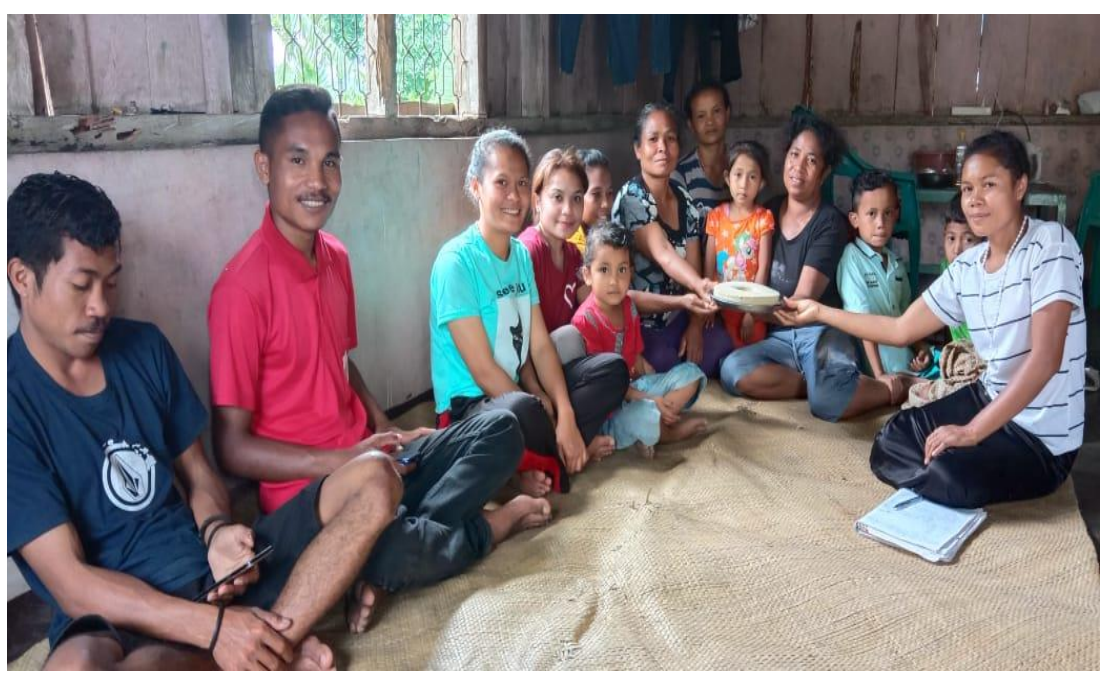

Gambar 2.6 Tim dan Mitra bersama-sama mencicipi bolu pisang 
Dalam struktur rumah tangga, penghasilan keluarga masih mengandalkan penghasilan suami. Hal ini disebabkan oleh minimnya pengetahuan dari para ibu rumah tangga tentang cara menambah penghasilan, juga disebakan oleh kurangnya informasi, motivasi, dan pelatihan dari pihak luar dalam upaya menumbuhkan kreativitas ibu rumah tangga. Kegiatan PKM ini dilaksanakan bertepatan dengan hari-hari menjelang hari raya natal, maka bolu pisang dijadikan sebagai camilan natal di semua rumah mitra. Hal ini berkontribusi positif bagi para ibu rumah tangga karena merupakan pengalaman baru bagi mereka. Pada natal sebelumnya, mereka tidak menyiapkan camilan apa pun karena biaya untuk membuat camilan-camilan natal lainnya lumayan membebani mereka. Selain untuk dimakan, bolu pisang sempat dijual di sekitar KBG St. Lukas. Program PKM yang diadakan oleh tim hendaknya menjadi awal yang baik bagi mitra, mitra lebih geliat untuk aktif dalam menanggulangi kebutuhan-kebutuhan dalam hidup berumah tangga. Dalam perencanaan awal, mitra dari kegiatan ini adalah semua IRT (petani) di Paroki St. Montfort Poco. Akan tetapi, hal ini tidak bisa dilakukan karena dibatasi waktu, kegiatan ini dilaksanakan bersamaan dengan kegiatan KKN Mahasiswa Unika Santu Paulus Ruteng, dan program PKM dilaksanakan di tengah pandemi covid-19. Oleh karena itu, tim berharap agar para IRT KBG St. Lukas bisa berbagi pengalaman ini dengan para IRT lainnya yang tidak sempat menjadi mitra dari kegiatan ini.

\section{KESIMPULAN}

Program pengabdian kepada masyarakat dilakukan oleh dosen dan mahasiswa yang sedang melakukan KKN memberikan pengaruh yang positif bagi para ibu rumah tangga kelompok umat basis gereja Santu Lukas Poco. Program PKM ini memberikan pengalaman yang baru bagi mitra dan membuka wawasan mereka untuk kegiatan-kegiatan lainnya dan selanjutya. Pelatihan pembuatan bolu pisang telah menyadarkan para ibu rumah tangga untuk menggali semua potensi-potensi mereka yang belum dikembangkan demi menambah penghasilan kelurga. Kegiatan PKM ini disambut dengan baik dan antusias oleh mitra, mitra tetap mengharapkan agar kegiatan-kegiatan serupa dilakukan lagi di tempat mitra. Ada juga mitra yang berani mengusulkan kegiatan lainnya tetapi membutuhkan bimbingan dan fasilitasi dari tim Unika Santu Paulus Ruteng. Persoalan ekonomi yang baik di desa perlu dipikirkan oleh semua pihak. Sangat banyak para ibu rumah tangga yang memiliki potensi yang baik, yang membutuhkan sentuhan dari berbagai pihak untuk dikembangkan, sehingga tim sempat menyarankan pemerintah desa untuk mengadakan kegiatan-kegiatan kecil yang dapat menambah wawasan para ibu rumah tangga tentang bagaimana mendapatkan uang sehingga membantu meningkatkan ekonomi keluarga.

\section{DAFTAR PUSTAKA}

Retno, D.T. \&Nuri, W. (2011). Pembuatan Bioetanol dari Kulit Pisang. Pros. Semin. Nas. Tek. Kim. "Kejuangan" Pengemb. Teknol. Kim. untuk Pengolah. Sumber Daya Alam Indones

Sayangbati, F., dkk. (2013). KarakteristikFisikokimiaBiskuitBerbahanBakuTepung Pisang Goroho (Musa acuminate,sp). COCOS

Aryani, T.M., Mu'awanah, I. A. U., \& Widyantara, A. B. 2018. Karakteristik Fisik, Kandungan Gizi Tepung Kulit Pisang dan Perbandingannya terhadap Syarat Mutu Tepung Terigu. JRST (Jurnal Ris. Sains dan Teknol. doi: 10.30595/jrst.v2i2.3094.

Miller, K. C. (2012). Plasma Potassium Concentration and Content Changes After Banana Ingestion in Exercised Men. Journal of Athletic Training, 47(6), 648- 
654. doi:10.4085/1062-6050-47.6.05

Tulus, T. H. (2011). Development of Micro, Small and Medium Enterprises and Their Constraints: A Story from Indonesia. Gadjah Mada International Journal of Business, 13(1), 21. doi:10.22146/gamaijb.5492

Peter, T., \& Cathy, I. M. (2015). Networking for SMES in Uganda: A conceptual paper. African Journal of Business Management, 9(2), 43-49. doi:10.5897/ajbm2014.7534

Storey, D.J.(1994). Understanding the Small Business Sector. Thomson Learning Hassan, H., Tretiakov, A., Whiddett, D., \& Adon, I. (2014). Extent of Eprocurement Use in SMEs: A Descriptive Study. Procedia - Social and Behavioral Sciences, 164, 264-270. doi:10.1016/j.sbspro.2014.11.076

Nurdin, R. (2019). Peningkatan Kapasitas Produksi Usaha Wedang Uwuh Wonokromo Pleret Bantul Yogyakarta. KACANEGARA. Jurnal Pengabdian Pada Masyarakat, 2(1), 7. doi:10.28989/kacanegara.v2i1.354

Weerasiri, S. (2012). Attitudes and Awareness towards Environmental Management and its Impact on Environmental Management Practices (EMPs) of SMEs in Sri Lanka. Journal of Social and Development Sciences, 3(1), 1623. doi:10.22610/jsds.v3i1.681

Wiyono, Sl. (2006). Managemen Potensi Diri. Jakarta:PT Grasindo

Zaima, Samino, Mariza, A., dan Kurniasari, D. (2020). Konsumsi Pisang dapat MenurunkanTekanan Darah pada Lansia.Jurnal Kebidanan Malahayati. 6 (1), 77-83. 